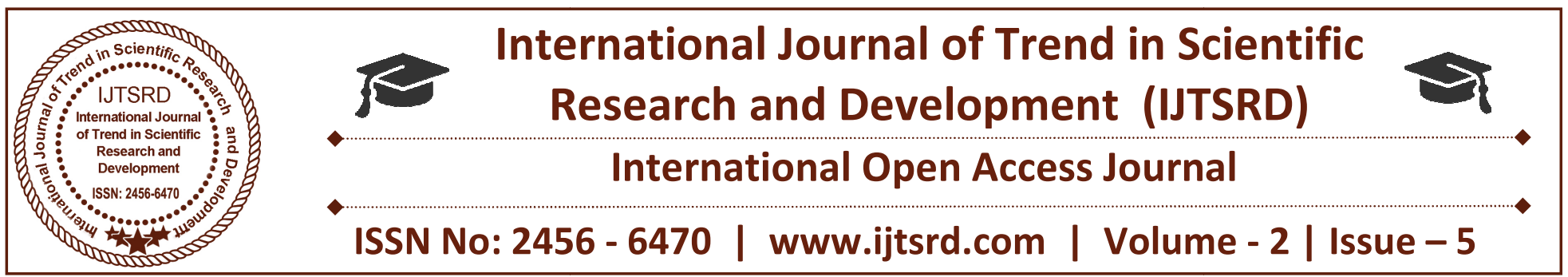

\title{
Load Shedding Management
}

\author{
Itika Sharma ${ }^{1}$, Shavet Sharma ${ }^{2}$ \\ ${ }^{1}$ M.Tech Scholar, ${ }^{2}$ Assistant Professor \\ Department of Electrical Engineering, Sri Sai College of Engineering \& Technology \\ Badhani, Pathankot, Punjab, India
}

\begin{abstract}
In our country we are facing tremendous problems because of electricity shortage and the J\&K state is on top. We are considered rich in production of electricity but the truth is we are not getting the desired. The solution is implementation of latest and emerging technologies like IOT and Microcontrollers in electrical domain. The paper describes the need of technology for load shedding process.
\end{abstract}

\section{KEYWORD: Sensor, IOT.}

\section{INTRODUCTION}

Load-shedding is a process by which the electrical authority handles the dearth of the electrical power being consumed by the society. Shedding is done to minimize the load being consumed by the society through several substations which are connected to the main power station. When the frequency of the power generator falls down, it fails to generate the required power. As a result the authority lacks the scheduled amount of power \& this leads the authority to perform a shedding. And the main station orders the sub-stations to cut some of the feeders for a certain period of time \& thus the shedding procedure continues. This work is required for load shedding time management which is used when the electricity demand exceeds the supply and there comes a need for manually switching ON/OFF the electrical devices in time. Hence we need a system that eliminates the manual operation by automatically switching the load $\mathrm{ON} / \mathrm{OFF}$.

The technique to of reducing power usage and energy consumption by both consumers and businesses has never been stronger. A rise in population, increased investments and growing economy all put a high

demand on electricity consumption which cannot be possible from the present capacity. One year of energy consumption can now beat the energy production rate of the previous half century. Demand response instead relies on specific devices, to reduce power, ON or completely shut down high-energyusage machines and components during peak demand times, or otherwise balance, usage between high- and low-demand cycles. This strategy is often referred to as load shedding. Load shedding is the system which is designed to distribute the available power to consumers. If it is used effectively, can help both the utility company and the customer to conserve energy and reduce costs. This helps to reduce brownouts, which can occur when energy usage exceeds the amount of energy that is available. Managing the power consumption and more evenly spacing it allows power companies to avoid scaling for additional power production. The energy provider is responsible for signalling that it's time for customers to make the necessary adjustments to power-consuming devices. This is accomplished by directly notifying Customers about load shedding time interval. Till now to generate the electricity bill man power is used and also to cut off the power, if the User fails to pay the bill on or before Due Date, again man power is required. Once user pays the bill, to get the power connection back he might require waiting a day. The proposed system is designed to address all these problems efficiently and avoids manual intervention in generating electricity bill and to automate the power cut off and power connection to the user.

\section{Sensors}

Sensors are devices that are frequently used to detect and respond to electrical or optical 
signals. A sensor converts the physical parameter (for example: temperature, blood pressure, humidity, speed, etc.) into a signal which can be measured electrically.

\section{Types of Sensors}

The most frequently used different types of sensors are classified based on the quantities such as Electric current or Potential or Magnetic or Radi sensors, Humidity sensor, Fluid velocity or Flow sensors, Pressure sensors, Thermal or Heat or Temperature sensors, Proximity sensors, Optical sensors, Position sensors, Chemical sensor, Environment sensor, Magnetic switch sensor etc.

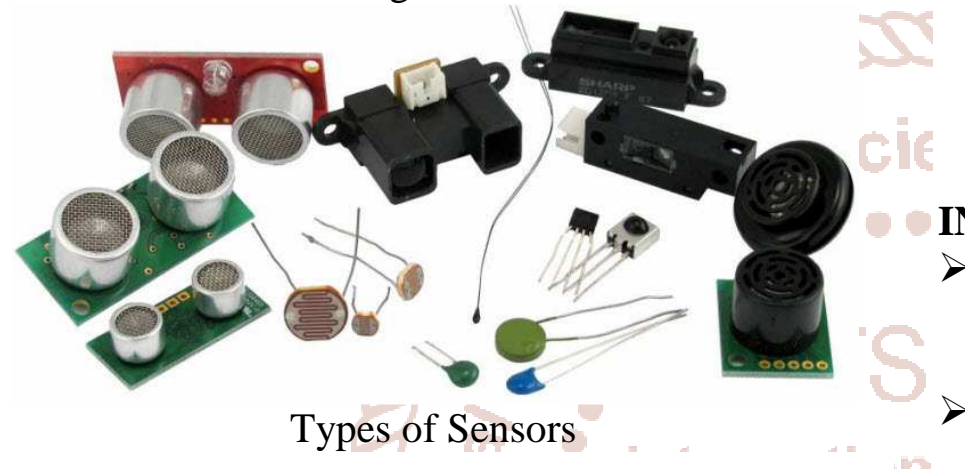

\section{Microcontrollers} Microcontrollers

A microcontroller is a solitary chip microcomputer fabricated from VLSI fabrication. A micro controller is also known as embedded controller. Today various types of microcontrollers are available in market with different word lengths such as 4bit, 8bit, 64bit and 128bit microcontrollers.

\section{Types of Microcontrollers}

Microcontrollers are divided into categories according to their memory, architecture, bits and instruction sets. The types are described below:

\section{BITS:}

8 bits microcontroller executes logic \& arithmetic operations. Examples of 8 bits micro controller is Intel 8031/8051.

$>16$ bits microcontroller executes with greater accuracy and performance in contrast to 8-bit. Example of 16 bit microcontroller is Intel 8096.

> 32 bits microcontroller is employed mainly in automatically controlled appliances such as office machines, implantable medical appliances, etc. It requires 32-bit instructions to carry out any logical or arithmetic function.

\section{MEMORY:}

$>$ External Memory Microcontroller - When an embedded structure is built with a microcontroller which does not comprise of all the functioning blocks existing on a chip it is named as external memory microcontroller. For illustration- 8031 microcontroller does not have program memory on the chip.

Embedded Memory Microcontroller - When an embedded structure is built with a microcontroller which comprise of all the functioning blocks existing on a chip it is named as embedded memory microcontroller. For illustration- 8051 microcontroller has all program \& data memory, counters \& timers, interrupts, I/O ports and therefore its embedded memory microcontroller.

\section{INSTRUCTION SET:}

$>$ CISC- CISC means complex instruction set computer, it allows the user to apply 1 instruction as an alternative to many simple instructions.

RISC- RISC means Reduced Instruction Set Computers. RISC reduces the operation time by shortening the clock cycle per instruction.

\section{MEMORY ARCHITECTURE:}

$>$ Harvard Memory Architecture Microcontroller

Princeton Memory Architecture Microcontroller

\section{IOT Technology}

The IOT is rapidly becoming a reality that surrounds us and intersects with many aspects of our lives. Pervasive connectivity and advances in ICT technologies have made possible the connection of more and more devices to the Internet. This is leading to a new wave of applications that have the potential to dramatically improve the way people live, learn, work, and entertain themselves. Sensors play a key role in connecting the physical world (temperature, $\mathrm{CO}_{2}$, light, noise, moisture) with the digital world of IOT. Availability of this data can make us more proactive and less reactive in our interaction with the world around us (Evans, 2011).

The IOT is the next evolution of the Internet. The success of IOT will be driven by applications that deliver tangible improvements to people's everyday lives. Sensors are likely to play a central role in providing the data streams upon which these applications can be built. For example, mobile and home-based environmental monitors allow people to 
track ambient air quality. They can use this data to either modify their environment or alter their behavior in order to maintain their health and wellness. As the value and impact of these applications reach widespread public visibility, the need for both improved and new sensor technologies is likely to grow rapidly. The IOT is very important for electrical domain like remote monitoring of power grids, smart energy meters, and programmable interface based load shedding management.

\section{Conclusion:}

In this paper I have briefly described technical aspects for electrical domain. The IOT is the very special technology used to control hardware devices using internet technology. The paper is about technologies that can be used for load shedding management.

\section{REFERENCES:}

1. J. O. Petinrin and Mohamed Shaaban, "Smart Power Grid: Technologies and Applications" International conference on Power and Energy (PECon) 2-5 December 2012.

2. V. Preethi and G. Harish, "Design and Implementation of Smart Energy Meter" Inventive computation Technologies (ICICT), International conference on 26-27 August 2016.

3. O. HomaKesav and B. Abdul Rahim, "Automated Wireless Meter Reading System for Monitoring and Controlling Power Consumption" International Journal of Recent Technology and Engineering Volume-1, Issue- 2, June 2012

4. Ashna, K.; George, S. N., "GSM based automatic energy meter reading system with instant billing," in Automation, Computing, Communication, Control and Compressed Sensing (iMac4s), 2013 International Multi-Conference on, vol., no., pp.6572, 22-23 March 2013.

5. R. Dhananjayan, E. Shanthi, "Smart Energy Meter with Instant Billing and Payment", International Journal of Innovative Research in Computer and Comm. Engineering, Vol.2, Issue 1, Mar 2014.

6. Maity, T.; Das, P. S., "Intelligent Online Measurement and Management of Energy Meter Data through Advanced Wireless Network," in Devices and Communications (ICDeCom), 2011 International Conference on, pp.1-4, 24-25 Feb. 2011.

7. M d. Wasi-ur-Rahman, Mohammad Tanvir Rahman, Tareq Hasan Khan and S. M. Lutful
Kabir, "Design of an Intelligent SMS Based Remote Metering System", IEEE International Conference on Information and Automation, 2009.

8. Bharat Kulkarni, "GSM Based Automatic Meter Reading System Using ARM Controller", International Journal of Emerging Technology and Advanced Engineering, Vol 2, Issue 5, May 2012).

9. Data Sheet - Texas Instruments of ULN2003 Rekha, A, Dr. Rathina Kumar, M., Ashok Kumar, N., Research Article An Intelligent Load Shedding To Improve Power System Congestion published in 13 April 2013

10. Datasheet of AT89S52 microcontroller from Atmel [online] available. www.atmel.com/images/doc0265.pdf

11. Data Sheet - Texas Instruments of ULN2003 [online] www.ti.com/lit/ds/symlink/uln2003a.pdf [4] MVP Rao - A Research in Real Time Scheduling Policy for Embedded system-2009 the paper available at at www.clei.org/cleiej/papers/v12i2p4.pdf

12. DS1307 II Part Number Search - Maxim datasheets.maximintegrated.com/en/ds/DS1307.pd f [6] Demand for electricity changes through the days www.eia.gov

13. Electricity

Demand http://www.mpoweruk.com/electricity_demand.ht $\mathrm{m}$

14. Sushma .S. R, Sowmya .P, SeethaLakshmi .H. R, Sowmyashree .S. R "Automated Load Shedding and Notification to the Consumers using GSM" 2017, International Journal of Engineering Science and Computing.

15. Prof. S. K. Bhatia, Kshirsagar Navin H., Lad Sayali S, Waghmare Namdev N " Auto Load Shedder for Electricity Board Using GSM Technique" 2015, International Engineering Research Journal (IERJ), Volume 2 Issue 1.

16. Smita Das, Agnivesh Pandey, NirmalyaKar"Automated Load Shedding Period Control System" 2015, https://www.researchgate.net/publication/2662692 14.

17. Patil P T, Dattatrayaraut, Sagar Sutar, Sandesh Narute "GSM Based Wireless Load-Shedding Management System for Non-Emergency 
Condition" 2015, International Journal of modern Trends in Engineering and Research, Volume 02, Issue 01.

18. Snehal K Gosavi. Khushbu D Badgujar. PrafullaP.Chaudhari, "Electricity And Load Shedding Monitoring" 2015, International Journal of Advanced Research in Electronics and Communication Engineering, Volume 4, Issue 3.

19. GhazanfarShahgholian “ Effect of Load Shedding Strategy on Interconnected Power Systems Stability When a Blackout Occurs" 2012, International Journal of Computer and Electrical Engineering, Vol. 4, No. 2.

20. DwijenRudrapal“Automated Load Shedding Period Control System" 2011, International Journal on Computer Science and Engineering, Vol. 3 No. 5.

21. Y. Hu, S. Sundara, T. Chorma, and J. Srinivasan, "Supporting rfid-based item tracking applications in oracle dbms using a bitmap data type," in VLDB '05: Proceedings of the 31st international conference on Very large data bases. VLDB Endowment, 2005, pp. 1140-1151.

22. M. A. Nascimento, M. T. Ozsu, D. Kossmann, R. J. Miller, J. A. ' Blakeley, and K. B. Schiefer, Eds., (e)Proceedings of the Thirtieth International Conference on Very Large Data Bases, Toronto,
Canada, August 31 - September 3 2004. Morgan Kaufmann, 2004.

23. R. Kimball, "Rfid tags and smart dust," http://www.intelligententerprise.com/030718/612 warehouse $1 \backslash 1$.jhtml.

24. B. Violino, "Rfid opportunities and challenges," http://www.rfidjournal.com/article/articleview/537

25. I. Corp., “Tomorrow's high performance network," http://developer.intel. com/technology/comms/perfnet/index.htm.

26. T. Hassan and S. Chatterjee, taxonomy for RFID," in HICSS '06: Proceedings of the 39th Annual Hawaii International Conference on System Sciences. IEEE Computer Society, 2006, p. 184.2.

27. C. Martins, "RFID data management: It's not the mass, it's the momentums," AIM Global, 2005.

28. S. R. Jeffery, G. Alonso, M. J. Franklin, W. Hong, and J. Widom, "A pipelined framework for online cleaning of sensor data streams," in ICDE '06: Proceedings of the 22nd International Conference on Data Engineering. IEEE Computer Society, 2006. 